\title{
Eficiência da luz solar refletida e desempenho de dispositivos de sombreamento
}

\author{
Reflected sunlight efficiency and the performance of \\ shading devices
}

\section{Marlise Lila Silva Carvalho \\ Ricardo Carvalho Cabús}

\section{Resumo}

A

quantidade de luz natural refletida e sua distribuição no interior da edificação variam de acordo com diferentes padrões de dispositivos de sombreamento. No caso dos brises, quantidade de peças, especularidade e refletância das superfícies são capazes de influenciar o desempenho da iluminação e o aproveitamento da luz solar. O objetivo desta pesquisa é estudar o desempenho de dispositivos de sombreamento em salas de aula com relação à eficiência da luz solar refletida, índice proposto, que relaciona a componente de luz solar refletida com a iluminância global. Foram definidas três variáveis desses dispositivos: número de peças, especularidade e refletância, e os modelos resultantes foram analisados quanto à eficiência da luz solar refletida, na cidade de Maceió. O programa utilizado para simulações computacionais foi o TropLux. Análises estatísticas foram desenvolvidas para identificar as variáveis de maior impacto para o índice. Os resultados mostraram que a refletância dos dispositivos é a variável que mais influencia o índice de eficiência da luz solar refletida, podendo incrementá-lo em até $142 \%$. Diante dos resultados obtidos, pode-se afirmar que é possível ampliar o aproveitamento da luz solar através da variação de características de dispositivos de sombreamento, trazendo benefícios para a iluminação natural no ambiente.

Palavras-chave: Iluminação natural. Luz solar refletida. Dispositivos de sombreamento.

\footnotetext{
Abstract

The amount of reflected daylight and its distribution within a room varies according to different types of shading devices. In the case of brises, thenumber of slats, the specularity and the reflectance of the surfaces can influence the performance of daylighting and the use of sunlight. The aim of this study is to investigate the performance of shading devices in classrooms, taking into account reflected sunlight efficiency (proposed index), which relates the reflected sunlight component to global illuminance. The study chose three variables related to these devices: number of pieces, specularity and reflectance. The resulting models were analysed for the efficiency of reflected sunlight, in Maceió. The program used for the computational simulations was TropLux. Statistical analyses were performed in order to identify the variables with greatest impact on reflected sunlight efficiency. The results showed that the reflectance of the devices is the variable that most positively influences reflected sunlight efficiency, increasing the index by up to $142 \%$. The conclusion is that it is possible to increase the use of sunlight through the variation of certain characteristics of shading devices, bringing benefits to the daylighting of indoor environments.
}

Recebido em 21/02/19 Aceito em 06/06/19 


\section{Introdução}

Diversos estudos apontam que as características físicas do ambiente escolar, sobretudo da sala de aula, são fatores relevantes para o bom desenvolvimento das atividades e, consequentemente, para o desempenho dos usuários (BARRETT et al., 2015), contribuindo ainda para promoção da saúde (BOYCE, 2009; HESCCHONG..., 2003). Torna-se, portanto, relevante analisar o ambiente construído desses espaços de ensino, a fim de investigar sua adequação à realidade climática, estimulando o uso da iluminação natural nessa tipologia de edificação.

Sob condições de céu claro e parcialmente nublado, o entorno e também os elementos arquitetônicos de proteção são convertidos em importantes fontes de luz difusa. Assim, a iluminação natural interior pode depender mais da luz solar refletida do que da luz natural direta (HOPKINSON; PETHERBRIDGE; LONGMORE, 1975). Segundo Baker e Steemers (2002), o projeto de iluminação solar aplica-se quando a luz solar é a condição predominante. Deve-se estar atento ao potencial da luz refletida por superfícies naturais e artificiais. Planejar a forma e as características das superfícies torna-se um importante recurso para o aproveitamento da luz solar refletida.

Com a inserção desses elementos de controle a trajetória da luz solar refletida para o ambiente é modificada, bem como a quantidade total admitida. Os dispositivos de sombreamento podem ser projetados para obstruir a visão do céu apenas o necessário para o sombreamento, refletindo a luz solar para o ambiente e minimizando essa perda (LAM, 1986; BAKER; STEEMERS, 2002; SOUZA; SANTOS, 2012).

Este trabalho pretende considerar a contribuição desses dispositivos para a luz solar refletida para o interior do ambiente. Para a identificação dessa contribuição, foi desenvolvido o índice de eficiência da luz solar refletida, proposto nesta pesquisa.

A quantidade de luz natural refletida e sua distribuição espacial no interior da edificação variam de acordo com diferentes padrões de dispositivos. No caso dos brises, a quantidade de peças, as características de reflexão e refletância das suas superfícies são capazes de influenciar o desempenho da iluminação e o aproveitamento da luz solar no ambiente (PEREIRA, 1992; KIM; KIM, 2010; LIMA; BITTENCOURT, 2012; LEUNG; RAJAGOPALAN; FULLER, 2013; GUTIERREZ et al., 2019). Para aplicação do índice de eficiência da luz solar refletida, foi definido um estudo paramétrico baseado na variação dessas características em sistemas de sombreamento compostos de brises. A partir daí foi possível identificar as características que mais influenciam o aproveitamento da luz solar na forma refletida.

A relevância do uso desse índice está na identificação e classificação de dispositivos mais eficientes, auxiliando decisões na fase inicial de concepção dos projetos. $\mathrm{O}$ conhecimento desse fenômeno possibilita que sejam repensados o acesso e a forma de quantificação da luz solar nos ambientes internos, contribuindo, ainda, para a previsão de ambientes mais confortáveis e eficientes energeticamente.

\section{Revisão bibliográfica}

Em climas ensolarados, a luz solar refletida em superfícies exteriores como solo, construções do entorno e dispositivos de sombreamento é uma fonte de iluminação útil para os ambientes e sua utilização pode ser otimizada diante da variação de características das aberturas. Em cenários de cânions urbanos a luz natural mais disponível para as aberturas situadas nos andares inferiores dos grandes prédios é a luz refletida pelas edificações opostas que possuem os mais variados valores de refletância (LI et al., 2009). Diversos autores dedicaram seus estudos à análise da influência da luz refletida para o desempenho da iluminação natural em ambientes internos, como pode ser visto a seguir. Indo além, algumas pesquisas destacam-se pelo desenvolvimento de metodologias para estimar a presença dessa componente na iluminação interna.

Hopkinson, Petherbridge e Longmore (1975) analisaram os efeitos da luz solar refletida no solo e na fachada oposta à abertura sobre a distribuição da iluminação no interior do ambiente. Os resultados mostraram que a luz solar refletida na fachada reduz a diferença entre a componente refletida exterior em um ponto do ambiente a $1,50 \mathrm{~m}$ da abertura e um ponto a $6,00 \mathrm{~m}$ da abertura de cerca de $6: 1$ para aproximadamente 4:1, aumentando a uniformidade de iluminação. $O$ efeito da adição da componente refletida pelo solo seria reduzir ainda mais a diferença entre os pontos de 6:1 para 3:1.

Cabús (2002) analisou a influência da luz natural refletida pelo solo em relação ao desempenho da iluminação natural nos ambientes do trópico úmido levando-se em consideração, entre outros aspectos, a influência de dispositivos de sombreamento para a componente refletida pelo solo. Através da divisão do solo em faixas paralelas à abertura do ambiente modelo, o autor identificou uma área onde o solo pode ser

192 Carvalho, M. L. S.; Cabús, R. C. 
mais eficiente em relação à iluminação no interior do ambiente (faixa $\mathrm{AB}$ da Figura 1), da qual o projetista pode tirar vantagem, a partir do uso de materiais com maiores valores de refletância, conforme mostra a Figura 1. Para o modelo analisado, pode-se delimitar a faixa $\mathrm{AB}$ a partir do ângulo $\mathrm{GSA}=45^{\circ}$ e $\mathrm{GHB}=70^{\circ}$, onde $\mathrm{G}$ é a base da fachada, $\mathrm{S}$ é o peitoril e $\mathrm{H}$ o topo da abertura.

Os resultados mostraram ainda que a marquise se destaca como mais eficiente em comparação com a prateleira de luz e brises horizontais, também investigados na pesquisa, e que a luz refletida pelo solo representa uma parte significativa da iluminação natural total no plano de trabalho "P", podendo chegar a $40 \%$.

Leal e Leder (2018) também investigaram a influência de variáveis do entorno nos níveis de iluminação de ambientes internos inseridos em um recorte urbano da cidade de João Pessoa, Paraíba. Entre as variáveis analisadas nos cenários urbanos de máxima ocupação estão dois coeficientes de reflexão das superfícies verticais do entorno construído: 58\%, que corresponde à média obtida no levantamento in loco; e 90\%, valor atribuído para comparação. Foi avaliado o comportamento dos cenários quanto à iluminância útil (UDI), à iluminância excessiva (eUDI) e à probabilidade de ofuscamento da luz natural (DGP). O coeficiente de reflexão máximo de $90 \%$ foi capaz de aumentar a área iluminada dos ambientes em $8,5 \%$. A ação da componente refletida externa influenciou, portanto, o desempenho da iluminação dos ambientes internos, reduzindo os efeitos do adensamento urbano.

\section{Dispositivos de captação e controle da luz}

$\mathrm{Na}$ maioria das edificações, janelas são as principais fontes de luz natural muitas vezes limitada pela presença de obstáculos como orientação, entorno construído e outros fatores que impedem a manutenção da iluminação no interior do ambiente (ELTAWEEL; YUEHONG, 2017). Alguns sistemas tem sido empregados com o objetivo de incrementar a iluminação, entre eles prateleiras de luz (MANGKUTO; ROHMAH; ASRI, 2018), venezianas (CHAN; TZEMPELIKOS, 2013), painéis prismáticos (RIBEIRO; CABÚS, 2015), brises, entre outros. Os projetistas dispõem, portanto, de uma grande quantidade de soluções para as envoltórias das edificações.

Aliado a isso, o avanço nos processos de simulação computacional e maior facilidade para o desenvolvimento de estudos paramétricos permitem acesso a soluções projetuais de dispositivos de sombreamento adequadas para diversas realidades climáticas (MARDALJEVIC et al., 2011). É importante também que, para a escolha de um sistema de abertura de uma edificação, seja levado em consideração o resultado plástico da solução e as suas demais funções, como, por exemplo, a possibilidade de vista ao exterior e de ventilação.

O brise é um elemento construtivo constituído, geralmente, por peças em formato de lâminas dispostas paralelamente e instaladas, na maioria das vezes, externamente à abertura, protegendo as superfícies verticais da edificação contra a radiação solar direta. A função desses dispositivos é sombrear com o objetivo de minimizar a incidência do sol sobre a abertura, proporcionando melhores condições de temperatura e controle da incidência solar e, consequentemente, reduzindo o consumo de energia com o condicionamento de ar (SILVA, 2014). Os brises permitem uma diversidade de soluções, variando em tamanho e forma, sem que suas características de sombreamento sejam alteradas, e têm sido objeto de estudo de pesquisas em contextos de clima diversos (DUBOIS, 2003; LIMA; BITTENCOURT, 2012; GUTIÉRREZ et al., 2019).

Dubois (2003) analisou o desempenho de quatro tipos de dispositivos de sombreamento, entre eles brises horizontais e inclinados a $45^{\circ}$, para um ambiente de escritório com uso de computadores orientado a sul, na Dinamarca (latitude $55.4^{\circ}$ Norte e longitude $12.35^{\circ}$ Leste). Os resultados mostraram que esses dispositivos apresentaram desempenho superior a marquises e toldos, por exemplo, e que garantiram níveis de iluminância adequados ao uso do espaço. Os brises a $45^{\circ}$ ainda apresentaram resultados satisfatórios em relação à luminância das superfícies do ambiente, reduzindo o risco de ofuscamento.

Figura 1 - Faixa $(A B)$ onde o solo pode ser mais eficiente em relação à iluminação no interior do ambiente

Fonte: Cabús (2002).

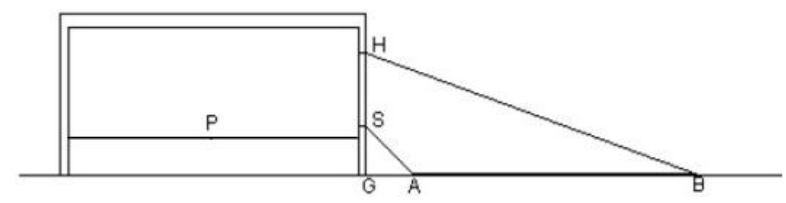


Lima e Bittencourt (2012) analisaram a influência da inclinação, espaçamento e refletância de brises horizontais de mesma máscara de sombra na iluminância média anual em ambientes de escritórios na cidade de Maceió. Os resultados apresentados indicam que a inserção de brises reduziu o ganho térmico pela radiação solar através da janela em todas as orientações, o que representa uma condição desejável na localidade em questão. Em relação à iluminância, observou-se que a inserção de brises resultou em redução das médias anuais de cada orientação em mais de 50\%, sendo que apenas as orientações norte e sul mantiveram os níveis entre 5001x e 2.0001x, faixa definida como desejável, segundo o método da iluminância útil de luz natural. Observou-se ainda que as orientações leste e oeste apresentaram maior tendência de reflexão da radiação solar para o interior do ambiente nos horários com presença de sol na fachada, indicando que a componente refletida da iluminação tem maior participação no resultado final do que nas orientações norte e sul.

Outro requisito importante que tem sido investigado é a capacidade de incremento da uniformidade das iluminâncias do ambiente proporcionada pelos brises (KIM; KIM, 2010; GUTIERREZ et al., 2019). Kim e Kim (2010) desenvolveram um dispositivo de sombreamento externo que consiste em um sistema de brises horizontais aplicado de forma inclinada a $20^{\circ}$ em relação ao plano da fachada, definido de acordo com a altura solar e o ângulo de incidência em períodos críticos do ano. Tal sistema foi comparado com o desempenho de persianas internas e com o mesmo sistema de brises horizontais aplicado de forma paralela à fachada em um ambiente de apartamento na Coreia. Os resultados demonstraram que o dispositivo inclinado apresentou melhor desempenho na área frontal e posterior do ambiente, aumentando respectivamente em $20 \%$ e $28 \%$ a iluminância média em relação à persiana interna.

Gutiérrez et al. (2019) compararam o desempenho de um sistema de brises a uma abertura sem proteção e a uma persiana, na cidade de Madri, analisando as orientações sul e sudeste. Os resultados mostraram que, considerando o nível de iluminação recomendada de 5001x, todos os sistemas promoveram iluminação adequada até a distância de 4,2m da janela. A partir dessa distância, todos os sistemas tiveram desempenho similar, com necessidade de iluminação elétrica complementar. O sistema de brises preveniram altos valores de iluminância próximo à janela, o que aconteceu no caso da janela sem proteção, e incrementaram a distribuição dos níveis de luz ao longo do ambiente em comparação aos demais casos. O sistema também manteve os maiores valores da autonomia de luz natural (daylight autonomy), chegando a 88\% na orientação sudeste.

No intuito de superar limitações de sistemas tradicionais, e a partir da utilização de novos materiais e tecnologias, os sistemas avançados de iluminação têm sido largamente empregados. Entre os vários tipos destacam-se os sistemas de brises com refletores especulares da luz. Essas superfícies são utilizadas para incrementar as propriedades de reflexão de dispositivos de sombreamento tradicionais (PEREIRA, 1992; BELTRÁN; PAPAMICHAEL; SELKOWITZ, 1997; KONIS; LEE, 2015; KONTADAKIS et al., 2017). Esse sistema, em integração com o teto do ambiente, por exemplo, pode permitir que a luz difusa atinja maiores distâncias no ambiente. Segundo Leung, Rajagopalan e Fuller (2013) existem relativamente poucos estudos sobre a performance de brises refletivos na literatura.

Leung, Rajagopalan e Fuller (2013) estudaram o comportamento de um sistema avançado para o redirecionamento de luz natural composto de brises com superfície refletiva especular instalado na parte superior da esquadria, em um ambiente de escritórios na cidade de Melbourne. O cenário utilizando o sistema foi comparado a um caso de referência, sem a proteção, e a outro cenário, onde o sistema de brises foi substituído por um painel de corte a laser. Os resultados da pesquisa mostraram que o sistema de brises foi responsável por aumentar os níveis de iluminância média no ambiente entre $10 \%$ e $82 \%$, sendo o maior ganho identificado na área mais distante da abertura, em comparação com o caso de referência. Em relação à análise qualitativa da iluminação natural, os resultados indicam que o sistema de brises proporcionou melhor distribuição da luz natural no ambiente, em comparação com o painel de corte a laser, indicando maior capacidade de condução da luz para áreas mais profundas do ambiente.

O objetivo do estudo de Konis e Lee (2015) foi comparar o potencial de iluminação natural de um sistema de brises ópticos instalados em abertura lateral, posicionada acima da altura do observador, com uma persiana convencional, na cidade de Berkeley, California (latitude $37^{\circ}$ Norte, longitude $122^{\circ}$ Oeste). O sistema de brises possui peças com acabamento espelhado (reflexão especular), enquanto a persiana possui acabamento fosco branco (reflexão difusa). A autonomia de luz natural (daylight autonomy) e a uniformidade da luminância do teto foram usadas para avaliação.

Os resultados mostraram que a luz refletida pelo sistema de brises para o plano de trabalho na parte posterior do ambiente foi suficiente para alcançar a iluminância mínima de 3001x em 100\% da área do piso por 69\% 
do tempo (fachada sul). Além disso, ao contrário do observado com a persiana, o sistema de brises não excedeu o limite estabelecido para desconforto visual (luminância média da abertura $>2.000 \mathrm{~cd} / \mathrm{m}^{2}$ ) em todo o período analisado. Os autores destacaram que a luz solar redirecionada pelo sistema de brises tem o potencial de reduzir significativamente o uso de energia elétrica, produzir uma distribuição mais uniforme da luminância no teto do ambiente e eliminar a possibilidade de ofuscamento.

Diversas pesquisas apresentam diferentes métodos para avaliar o comportamento da luz refletida levando-se em consideração parâmetros como refletância de superfícies do entorno e a geometria dos elementos construídos, como forma de buscar o maior aproveitamento dessa componente para a iluminância do ambiente interno (PEREIRA, 1992; KIM; KIM, 2010; LEUNG; RAJAGOPALAN; FULLER, 2013; LIMA; CARAM, 2015). Para que se busquem formas mais eficientes para a admissão da luz solar na forma refletida, é fundamental o conhecimento do comportamento desta componente no ambiente interno, bem como sua relação com o desempenho da iluminação natural.

\section{Parâmetros para avaliação dos dispositivos de sombreamento em relação à eficiência da luz solar refletida}

No caso de sistemas compostos de brises horizontais, a geometria engloba aspectos como potencial de mascaramento por orientação, número de peças, profundidade e espessura das peças, espaçamento, entre outros. Já as características das superfícies desses dispositivos podem variar de acordo com o tipo de reflexão que proporcionam. Entender a natureza da luz e seu controle por meio do fenômeno de reflexão é necessário para projetar as formas arquitetônicas.

Reflexão é o processo pelo qual uma parte da radiação que atinge um material deixa esse material, retornando a partir do mesmo lado da incidência da radiação. A geometria da radiação de saída é usada para caracterizar a reflexão, que é geralmente descrita como especular ou difusa (ILLUMINATING..., 2011). Se a superfície possui irregularidades que são pequenas comparadas ao comprimento de onda da radiação incidente, ela é considerada polida e resulta em reflexão especular. Nesse caso, o ângulo entre o raio refletido e a normal da superfície será igual ao ângulo entre o raio incidente e a normal. Materiais com superfícies espelhadas ou altamente polidas como o alumínio, por exemplo, possuem reflexão especular.

Se a superfície possui maior irregularidade, ela é considerada áspera e possui reflexão difusa, refletindo a radiação em vários ângulos (ILLUMINATING..., 2011). A maioria dos materiais disponíveis possui características de reflexão mista, sendo capaz de produzir reflexões difusas e especulares.

Avaliações dessas características em sistemas de brises são encontradas na literatura como análises paramétricas envolvendo dimensionamento e propriedades dos seus componentes, resultantes de estudos de caso levando-se em consideração diferentes realidades climáticas. O Quadro 1 resume as principais características físicas de sistemas de sombreamento com brises utilizadas em estudos paramétricos para avaliação da iluminação natural identificadas na revisão bibliográfica.

\section{Quadro 1 - Características de sistemas de sombreamento utilizadas em estudos de avaliação da iluminação natural}

\begin{tabular}{|l|l|}
\hline $\begin{array}{l}\text { Parâmetros utilizados em estudos com dispositivos de } \\
\text { Sombreamento tipo brises }\end{array}$ & \multicolumn{1}{|c|}{ Autores } \\
\hline Ângulo de sombreamento & Wima e Caram (2015) \\
\hline $\begin{array}{l}\text { Ângulo de sombreamento } \\
\text { Acionamente peças }(2017)\end{array}$ \\
\hline $\begin{array}{l}\text { Espessura das peças } \\
\text { Profundidade das peças } \\
\text { Percentual de permeabilidade visual do sistema em relação ao } \\
\text { plano normal à fachada }\end{array}$ & Cartana, Pereira e Berté (2016) \\
\hline $\begin{array}{l}\text { Ângulo de sombreamento } \\
\text { Espaçamento das peças } \\
\text { Refletância dos brises }\end{array}$ & Lima e Bittencourt (2012) \\
\hline $\begin{array}{l}\text { Porcentagem de área visível das peças } \\
\text { Refletância dos brises }\end{array}$ & Fiuza e Claro (2009) \\
\hline Especularidade & Gutiérrez et al. (2019) \\
\hline
\end{tabular}


Analisando os resultados dessas pesquisas, percebe-se que a refletância e a especularidade destacam-se como os parâmetros que mais influenciam a iluminação natural nos ambientes. A influência do número de peças foi pouco explorada nas pesquisas citadas e as características como espaçamento e espessura das peças resultaram em pouca alteração nos resultados.

No entanto, pouco se conhece a respeito da contribuição da luz refletida por sistemas compostos de brises, ainda que diversos autores tenham confirmado sua influência positiva para a iluminação natural. A lacuna identificada na bibliografia chama a atenção quando se trata particularmente da luz solar, energia abundantemente disponível nos trópicos e com potencial para reduzir gastos com energia artificial. Apesar de a literatura confirmar os benefícios trazidos por esses sistemas, a ausência de estudos paramétricos que analisem especificamente a contribuição da luz solar para a iluminação foi identificada.

\section{Método}

O modelo utilizado representa o espaço de uma sala de aula com capacidade para 40 alunos (ver Figura 2) e foi definido a partir do levantamento das salas de aula projetadas e construídas no Campus A. C. Simões da Universidade Federal de Alagoas durante o período de duração do Plano de Reestruturação e Expansão das Universidades Federais (REUNI), entre os anos de 2008 e 2012. As principais características do modelo encontram-se descritas na Tabela 1 e foram obtidas a partir da observação de características físicas das salas de aula levantadas.

Figura 2 - Modelo de sala de aula utilizado na pesquisa
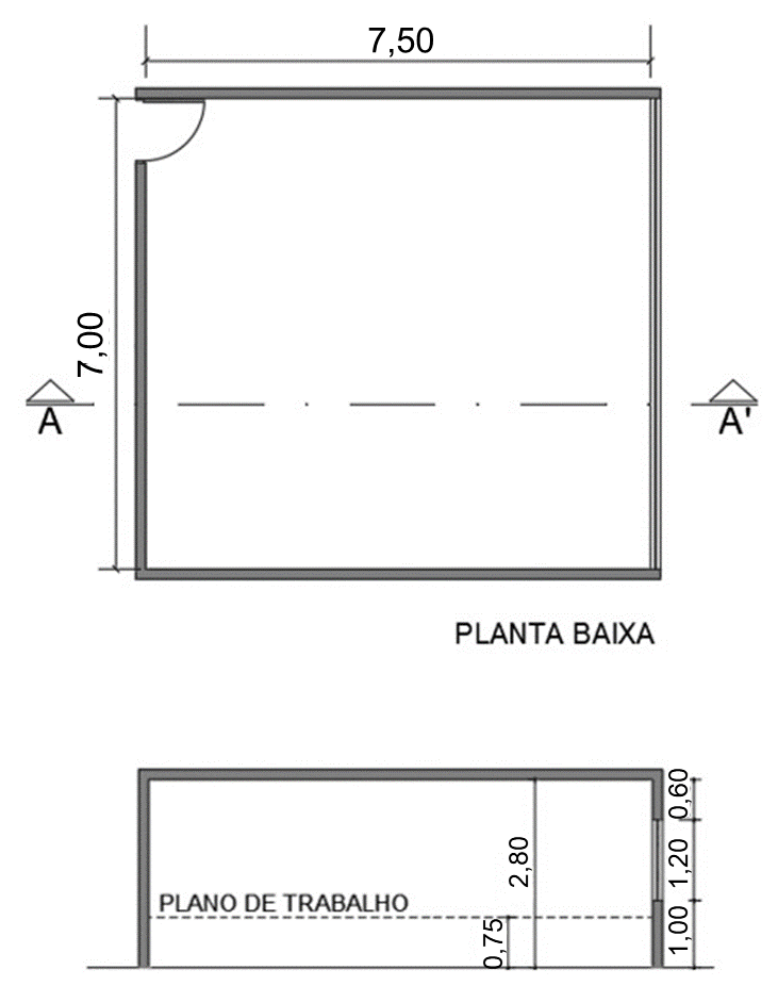

CORTE AA'

Tabela 1 - Características do modelo

\begin{tabular}{l|c}
\hline \multicolumn{2}{c}{ Características do modelo } \\
\hline Dimensões & $7,00 \mathrm{~m} \times 7,50 \mathrm{~m}$ \\
Área & $52,5 \mathrm{~m}^{2}$ \\
Pé-direito & $2,80 \mathrm{~m}$ \\
Refletâncias (piso/ parede/ teto) & $0,30 / 0,60 / 0,70$ \\
Abertura & $7,00 \mathrm{~m} \times 1,20 \mathrm{~m}$ (peitoril $1,00 \mathrm{~m}$ ) \\
\hline
\end{tabular}

196 Carvalho, M. L. S.; Cabús, R. C. 
O estudo foi realizado para a cidade de Maceió, Alagoas, latitude $9^{\circ} 40^{\prime}$ Sul e longitude $35^{\circ} 42^{\prime}$ Oeste. Com o intuito de obter dados anualizados de iluminância, foram considerados todos os dias do ano, entre $8 \mathrm{~h}$ e $16 \mathrm{~h}$ (hora solar), hora a hora. O período de estudo foi definido levando-se em consideração a simetria entre os horários da manhã e da tarde e a maior disponibilidade da luz solar.

Foram configurados três sistemas de proteção, a partir do uso de dispositivos horizontais, para as orientações norte, leste, oeste e sul. Foram utilizados os mesmos ângulos de proteção para os sistemas de mesma orientação, de modo que no período definido não houvesse luz solar direta no plano de trabalho, conforme mostra a Tabela 2, para que fosse analisada apenas a luz solar refletida pelos dispositivos. A Tabela 2 apresenta as máscaras de sombra e os ângulos $\alpha$ (horizontal) e $\gamma$ (vertical lateral esquerdo e direito) correspondentes para cada orientação.

Com base nos objetivos estabelecidos e na revisão bibliográfica, que destacou os parâmetros de maior influência sobre o desempenho da iluminação natural, foram definidas três variáveis dos sistemas de dispositivos a serem analisadas nesta pesquisa:
(a) número de peças;
(b) especularidade; $\mathrm{e}$
(c) refletância.

A primeira variável definida foi "número de peças", a partir do desenvolvimento de três sistemas de dispositivos com diferentes quantidades de peças para cada orientação. Os sistemas foram desenvolvidos de maneira que a área das peças totalizasse sempre o mesmo valor por orientação, mantendo-se assim a mesma área de exposição solar.

Cada modelo apresenta na sua nomenclatura a representação do sistema ao qual pertence, da sua especularidade ou difusividade e da sua refletância (ver Figura 3). A representação do sistema ao qual pertence o modelo é definido através das letras $a, b$ e $c$, que indicam a variação do número de peças. No caso das orientações norte e sul, os sistemas $a, b$ e $c$ correspondem, respectivamente, a dispositivos com uma, duas e quatro peças. Já nas orientações leste e oeste, a denominação dos sistemas corresponde a dispositivos com duas, quatro e oito peças.

A característica de reflexão dos dispositivos define se o tipo de reflexão é especular, difusa ou mista. Na nomenclatura, a letra $D$ indica o valor da refletância difusa do modelo, e a letra $E$ o valor da refletância especular. No caso de haver valores de refletância tanto para reflexão difusa, quanto para especular, o modelo se caracteriza como de reflexão mista. No caso de o valor de refletância difusa $D$ ser zero, o modelo em questão é totalmente especular, e no caso de o valor de refletância especular $E$ ser zero, o modelo é totalmente difuso.

Tabela 2 - Máscaras de sombra e ângulos para orientações norte, leste, oeste e sul para Maceió, Alagoas

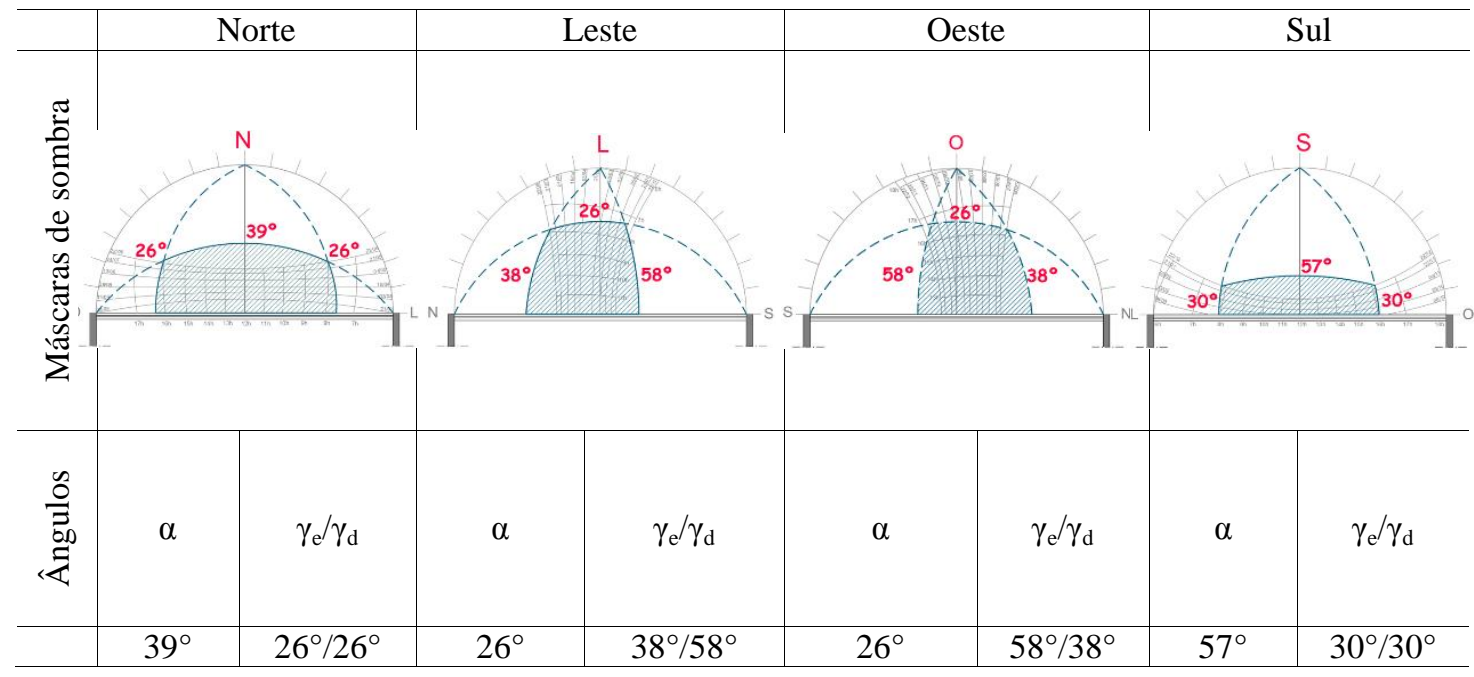


Figura 3 - Nomenclatura dos modelos utilizados

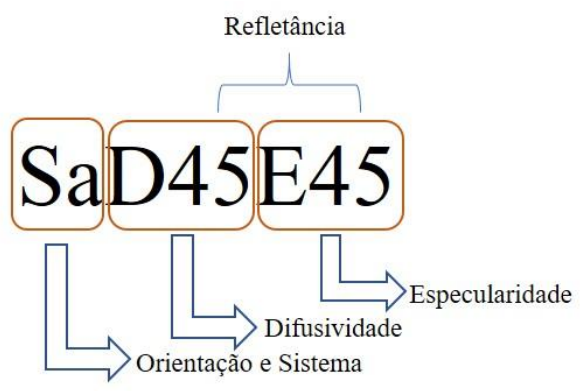

\section{Número de peças dos sistemas}

Para a análise da variação do número de peças, foi utilizada inicialmente a refletância $90 \%$ em todos os modelos estudados, dentro de cada grupo com reflexão difusa, mista e totalmente especular, conforme mostram os Quadros de 2 a 5, que resumem a matriz de simulação dessa variável para cada orientação. As demais refletâncias (de 10\% a 70\%) também foram utilizadas na análise. Não foi considerada a espessura das peças.

Nota-se que as orientações leste e oeste apresentam maior quantidade de peças nos seus sistemas, em comparação com as demais orientações. Isso se deve ao fato de que essa orientação exige maior proteção contra insolação direta no período definido para o estudo, no caso de dispositivos horizontais de sombreamento, conforme pode ser visto na Tabela 2.

\section{Especularidade dos dispositivos}

Para a análise da especularidade, a refletância total foi fixada em $90 \%$ em todos os cinco modelos de cada sistema, por orientação estudada. A mesma metodologia foi utilizada para criação dos modelos das demais orientações: foram definidos cinco modelos de dispositivos com reflexão especular variando entre $0 \%$ (modelos totalmente difusos) e 100\% (modelos totalmente especulares), possuindo três desses modelos reflexão mista (difusa e especular).

Nos três modelos com reflexão mista, a especularidade aumenta de forma crescente, sendo de $30 \%$ no primeiro modelo misto, de $45 \%$ no segundo e $60 \%$ no terceiro.

\section{Refletância das superfícies dos dispositivos}

Foram estabelecidos dois grupos diferentes para cada sistema: o grupo dos dispositivos difusos e o grupo dos dispositivos especulares. Cada um desses dois grupos possui cinco modelos, com refletâncias variando entre $10 \%$ e $90 \%$. Vale destacar que as refletâncias de $10 \%$ e $90 \%$, embora não sejam comuns entre os materiais utilizados na construção, foram adotados nesta pesquisa para garantia de maior amplitude desse parâmetro.

\section{Eficiência da luz solar refletida}

Para o desenvolvimento do índice de eficiência da luz solar refletida $\left(\eta_{\text {sr }}\right)$, definido e proposto nesta pesquisa, a componente de luz solar refletida média anual de cada modelo foi analisada separadamente e relacionada à iluminância média anual global no plano de trabalho. A partir da utilização desse índice, foi possível identificar a eficiência de cada sistema em refletir a luz solar para o interior do ambiente, contribuindo, assim, para um maior aproveitamento dessa fonte de luz na forma difusa.

O índice de eficiência de cada sistema de dispositivos em refletir a luz solar para o ambiente interno é dado pela Equação 1:

$\eta_{s r}=\frac{E_{s r}}{E_{g}} \times 100 \%$

Onde:

$\mathrm{E}_{\mathrm{g}}$ corresponde à iluminância global; e

$\mathrm{E}_{\mathrm{sr}}$ corresponde à iluminância relativa à componente de luz solar refletida.

198 Carvalho, M. L. S.; Cabús, R. C. 
Quadro 2 - Modelos para análise do número de peças dos dispositivos - orientação norte

\begin{tabular}{|c|c|c|c|c|c|c|c|c|}
\hline Orientação & \multicolumn{8}{|c|}{ NORTE } \\
\hline \multirow[b]{2}{*}{ Sistemas } & Sistema a & & & Sistema b & & & Sistema c & \\
\hline & & & & & & & & \\
\hline Modelos & \begin{tabular}{l|l} 
NaD90 & NaD45E45
\end{tabular} & NaE90 & NbD90 & NbD45E45 & NbE90 & $\mathrm{NcD90}$ & NcD45E45 & NcE90 \\
\hline
\end{tabular}

Quadro 3 - Modelos para análise do número de peças dos dispositivos -orientação leste

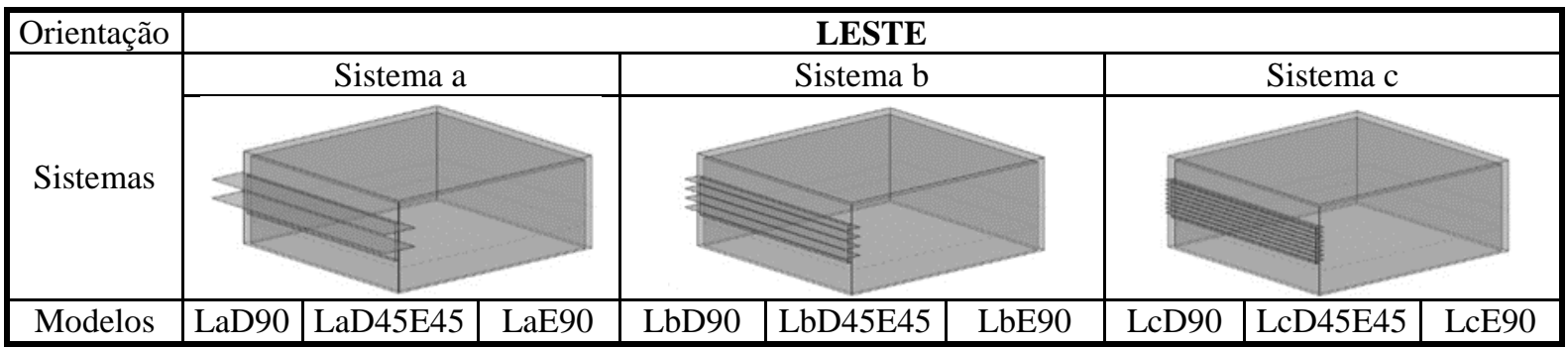

Quadro 4 - Modelos para análise do número de peças dos dispositivos - orientação oeste

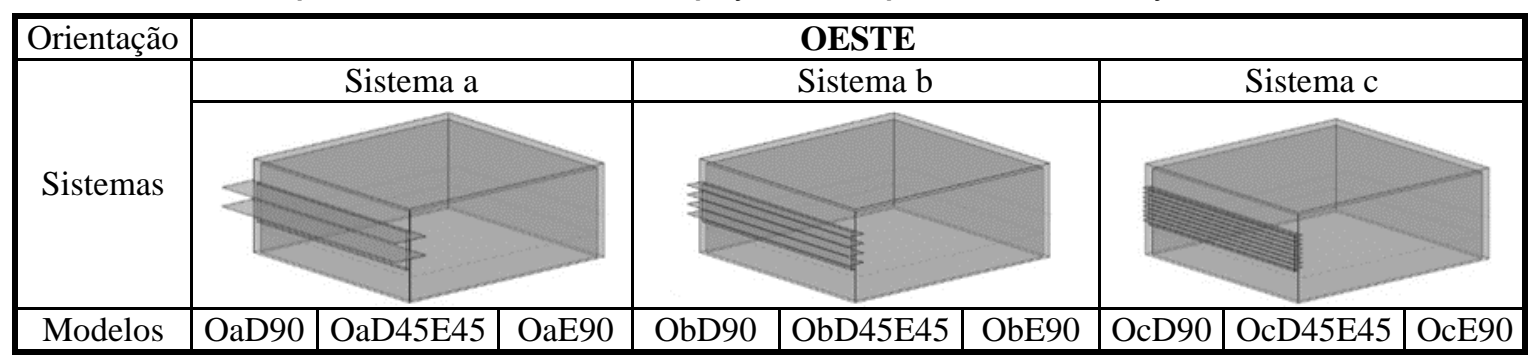

Quadro 5 - Modelos para análise do número de peças dos dispositivos - orientação sul

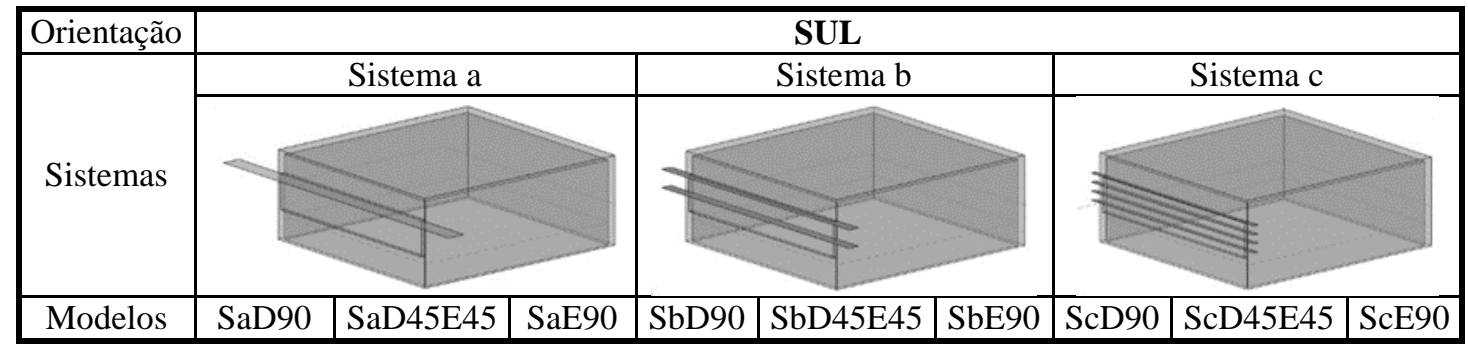

\section{Definição do software utilizado}

O programa TropLux 7 (CABÚS; RIBEIRO, 2015) foi utilizado para o desenvolvimento da pesquisa. Os algoritmos do TropLux baseiam-se em três conceitos fundamentais: o método do raio traçado (WARD; RUBINSTEIN, 1988), o método Monte Carlo aplicado à iluminação natural (TREGENZA, 1983) e o conceito de coeficientes de luz natural (TREGENZA; WATERS, 1983).

Os coeficientes de luz natural propostos por Tregenza e Waters (1983) fazem a relação da iluminância de uma dada superfície em função da luminância de uma determinada subdivisão do céu. No caso do TropLux, são utilizados dois tipos de subdivisão: para o cálculo da componente refletida é utilizada a proposta da CIE, que divide o céu em 145 partes, e para o cálculo da componente direta utiliza-se uma subdivisão com 5.221 partes, que traz melhorias na precisão dos resultados em função do tamanho angular do sol (CABÚS, 2005). 
O software, largamente referenciado em trabalhos técnico-científicos (LARANJA, 2010; RAMOS; GHISI, 2010; BECKER et al., 2011; ELETROBRAS-PROCEL, 2012; LAMBERTS; DUTRA; PEREIRA, 2014; HAREDY, 2016; WENA; HIYAMA; KOGANEI, 2017), permite que cada componente da iluminação no ambiente seja analisada separadamente, possibilitando a análise da luz solar refletida, objeto de estudo desta pesquisa. Em relação às características do ambiente interno, o TropLux permite utilizar formas complexas e configurar as características de reflexão das superfícies, sendo, portanto, uma ferramenta adequada de acordo com o objetivo desta pesquisa.

\section{Parâmetros de simulação}

Os dados foram calculados em uma malha de pontos definida pela norma da ABNT ISO/CIE 8995, que se baseia no tamanho e na forma da superfície de referência. Para o ambiente modelo em questão, a referida norma, no seu Anexo B, recomenda a utilização de uma malha de 9 x 8, totalizando 72 pontos de cálculo. O índice de eficiência da luz solar refletida e os indicadores de desempenho de cada ambiente foram comparados a partir da média dos pontos da malha.

De acordo com Cabús (2002), o céu parcialmente nublado é o tipo mais comum em Maceió, com 61,8\% de ocorrência, seguido do céu encoberto, com $25,8 \%$, e do céu claro, com 12,4\%. Foi utilizado nesta pesquisa o céu com distribuição dinâmica de luminâncias para a cidade de Maceió. Este céu escolhe um dos tipos de céu CIE (COMMISSION..., 2002), de acordo com sua probabilidade, no dia e na hora calculados, usando os estudos de Cabús (2002) e de Manhas (2016). O modelo de céu empregado utiliza a subdivisão de 145 e 5.221 partes conforme Cabús (2002).

\section{Análise dos resultados}

A análise dos resultados foi dedicada à aplicação do índice de eficiência da luz solar refletida e divide-se em dois tipos: análise exploratória e análise estatística.

A análise exploratória foi realizada inicialmente a partir da observação do comportamento do índice de eficiência da luz solar refletida $\left(\eta_{\mathrm{sr}}\right)$ frente aos parâmetros estabelecidos para a pesquisa, levando-se em consideração as orientações definidas. Inicialmente foi analisado o efeito da variável "número de peças".

A fim de verificar o comportamento das variáveis definidas na análise exploratória foi realizada a análise estatística dos dados, a partir do uso de regressão múltipla. O software utilizado para as análises estatísticas foi o Statistica, versão 7. Usando o método dos mínimos quadrados, a regressão permite avaliar o comportamento de uma variável dependente diante de duas ou mais variáveis independentes. Para tanto, foi necessário o ajuste dos modelos definidos, a fim de padronizar as categorias de cada variável investigada. Todos os parâmetros definidos foram utilizados na análise estatística, conforme mostra a Tabela 3, elaborada de acordo com as categorias estabelecidas para a orientação norte.

No caso das orientações leste e oeste, as categorias da variável "número de peças" são diferentes, uma vez que nessas situações os sistemas possuem maior quantidade de peças. Observa-se que a variável 03 "especularidade dos dispositivos" consiste em uma variável qualitativa dos dispositivos, referente à característica de reflexão das superfícies das peças, e, para que fosse incluída nesta etapa de análise, foi necessária sua conversão em valor numérico (1, 2 e 3), sendo o menor valor correspondente à situação de modelo difuso.

Para que fosse mantido o mesmo número de categorias de variáveis, neste caso três categorias, foram utilizadas três refletâncias, entre as cinco utilizadas na análise exploratória. Com a mesma finalidade, a variável 03 também foi reduzida para três situações de especularidade.

Também nesta etapa foi utilizado o mesmo número de categorias de variáveis. Os resultados da análise estatística de regressão foram apresentados na forma de planilha de efeitos estimados, na qual constam os valores dos efeitos de cada variável independente para a variação da eficiência da luz solar refletida, além de gráficos que relacionam a interação de duas variáveis.

\section{Resultados}

\section{Efeitos da variação do número de peças}

Em modelos com refletância de $90 \%$, a análise da orientação norte indicou que a inserção de mais peças pode resultar em maior aproveitamento da luz solar. Os modelos especulares apresentaram ganhos de $28 \%$ e 
correspondem ao grupo capaz de proporcionar maiores variações na eficiência. Os modelos com reflexão mista e difusos apresentaram ganhos de $17 \%$ e $11 \%$, respectivamente.

Analisando-se os modelos com refletâncias abaixo de $90 \%$ referentes à orientação norte (Tabela 4) observase que somente a partir da refletância de $70 \%$, no caso dos modelos difusos, e da refletância de 50\%, no caso dos modelos especulares, o aumento do número de peças resulta em ganhos para o aproveitamento da luz solar refletida.

Na orientação leste, o aumento no número de peças não resultou em variação significativa do índice de eficiência da luz solar refletida em nenhum dos grupos de dispositivos analisados, com refletância de $90 \%$. Tal comportamento também foi observado na orientação oeste. Na orientação sul a variação no desempenho dos três grupos de reflexão analisados também foi bem reduzida, o que pode ser melhor observado no gráfico da Figura 4, indicando que nessa orientação o desempenho de dispositivos difusos, mistos e especulares se aproxima.

\section{Efeitos da variação da especularidade}

Esta seção apresenta os efeitos da variação da especularidade na reflexão dos dispositivos para o índice de eficiência da luz solar refletida. Para esse fim, foram analisados modelos de dispositivos com mesma refletância, mas com diferente especularidade, dando origem a modelos difusos, mistos e totalmente especulares. Para cada sistema e orientação, esse conjunto de modelos foi avaliado.

Percebe-se a partir da Figura 5, que, embora todos os modelos possuíssem a mesma refletância (90\%), houve aumento dos índices de eficiência em todos os sistemas e orientações estudadas conforme a especularidade aumentava. Porém, em cada orientação e sistema de dispositivos foram observadas diferentes porcentagens de aumento da eficiência diante do incremento da especularidade.

$\mathrm{Na}$ orientação norte observou-se que os aumentos decorrentes da variação da reflexão totalmente difusa para totalmente especular foram mais expressivos no sistema com maior número de peças, no qual tal variação resultou em incremento de $38 \%$. O sistema com menor número de peças proporciona aumento de $20 \%$.

Tabela 3 - Variáveis e categorias para análise estatística - orientação norte

\begin{tabular}{|c|c|c|c|c|}
\hline Variável & Tipo & Definição & Categorias do modelo & $\begin{array}{l}\text { Categorias } \\
\text { estatísticas }\end{array}$ \\
\hline Variável 01 & Dependente & $\begin{array}{l}\text { Índice de eficiência de luz } \\
\text { solar refletida }\left(\eta_{\mathrm{sr}}\right)\end{array}$ & - & - \\
\hline \multirow{3}{*}{ Variável 02} & \multirow{3}{*}{ Independente } & \multirow{3}{*}{ Número de peças } & Sistema a- 01 peça & 1 \\
\hline & & & Sistema b- 02 peças & 2 \\
\hline & & & Sistema c- 04 peças & 4 \\
\hline \multirow{3}{*}{ Variável 03} & \multirow{3}{*}{ Independente } & \multirow{3}{*}{$\begin{array}{l}\text { Especularidade dos } \\
\text { dispositivos }\end{array}$} & Sem especularidade & 1 \\
\hline & & & $50 \%$ de especularidade & 2 \\
\hline & & & $100 \%$ de especularidade & 3 \\
\hline \multirow{3}{*}{ Variável 04} & \multirow{3}{*}{ Independente } & \multirow{3}{*}{$\begin{array}{l}\text { Refletância dos } \\
\text { dispositivos }\end{array}$} & 0,1 & 0,1 \\
\hline & & & 0,5 & 0,5 \\
\hline & & & 0,9 & 0,9 \\
\hline
\end{tabular}

Tabela 4 - Variação do índice de eficiência de luz solar refletida em relação ao aumento do número de peças, por refletância - orientação norte

\begin{tabular}{c|c|c}
\hline & \multicolumn{2}{|c}{ Variação de $\boldsymbol{\eta}_{\mathbf{s r}}(\%)$} \\
\hline Refletância (\%) & Difusos & Especulares \\
\hline 10 & -28 & -25 \\
30 & -18 & -9 \\
50 & -1 & 5 \\
70 & 2 & 17 \\
90 & 11 & 27 \\
\hline
\end{tabular}


Figura 4 - Gráfico de variação do índice de eficiência da luz solar refletida em relação ao aumento do número de peças - orientações norte, leste, oeste e sul; refletância 90\%; norte e sul= Sistema a- 01 peça, Sistema b- 02 peças, Sistema c- 04 peças; leste= Sistema a- 02 peças, Sistema b- 04 peças, Sistema c- 08 peças

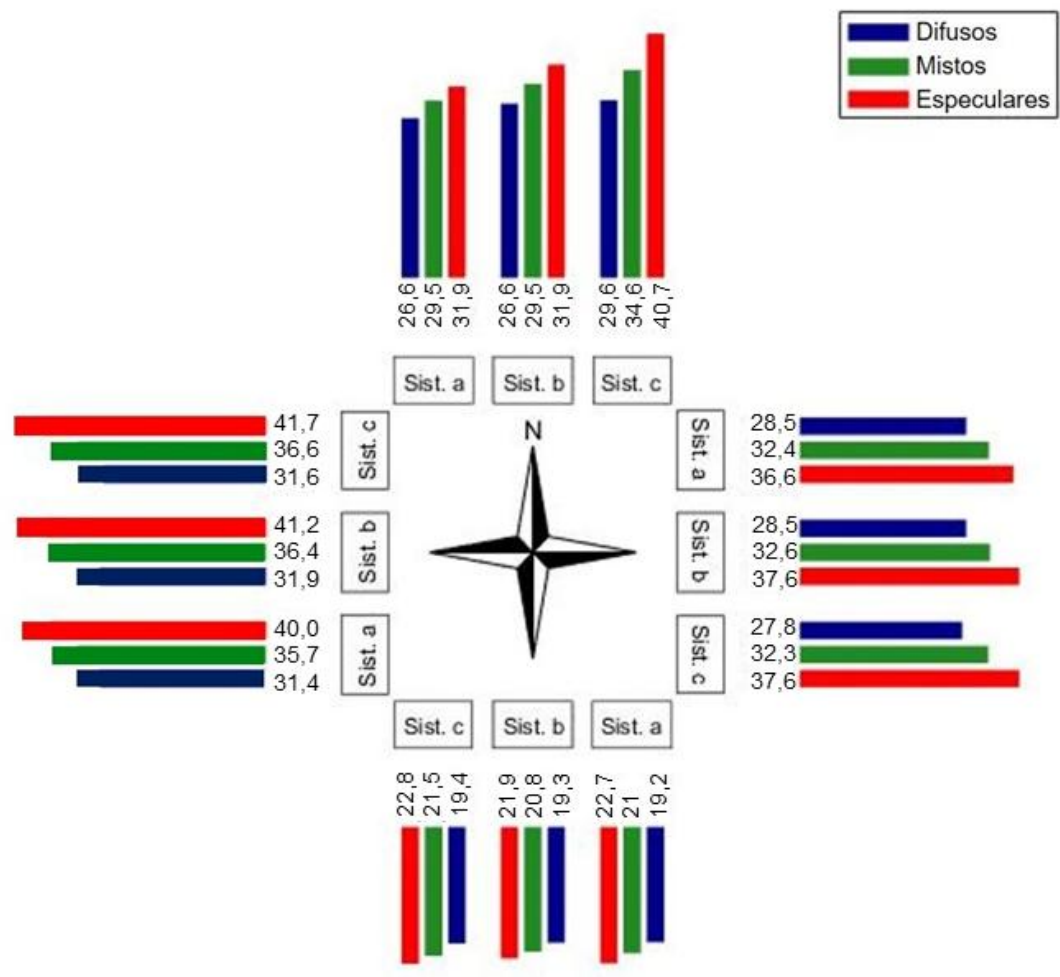

Figura 5 - Gráfico de variação do índice de eficiência da luz solar refletida em relação à especularidade dos dispositivos - orientações norte, leste, oeste e sul; refletância 90\%; norte e sul= Sistema a- 01 peça, Sistema b- 02 peças, Sistema c- 04 peças; leste= Sistema a- 02 peças, Sistema b- 04 peças, Sistema c- 08 peças

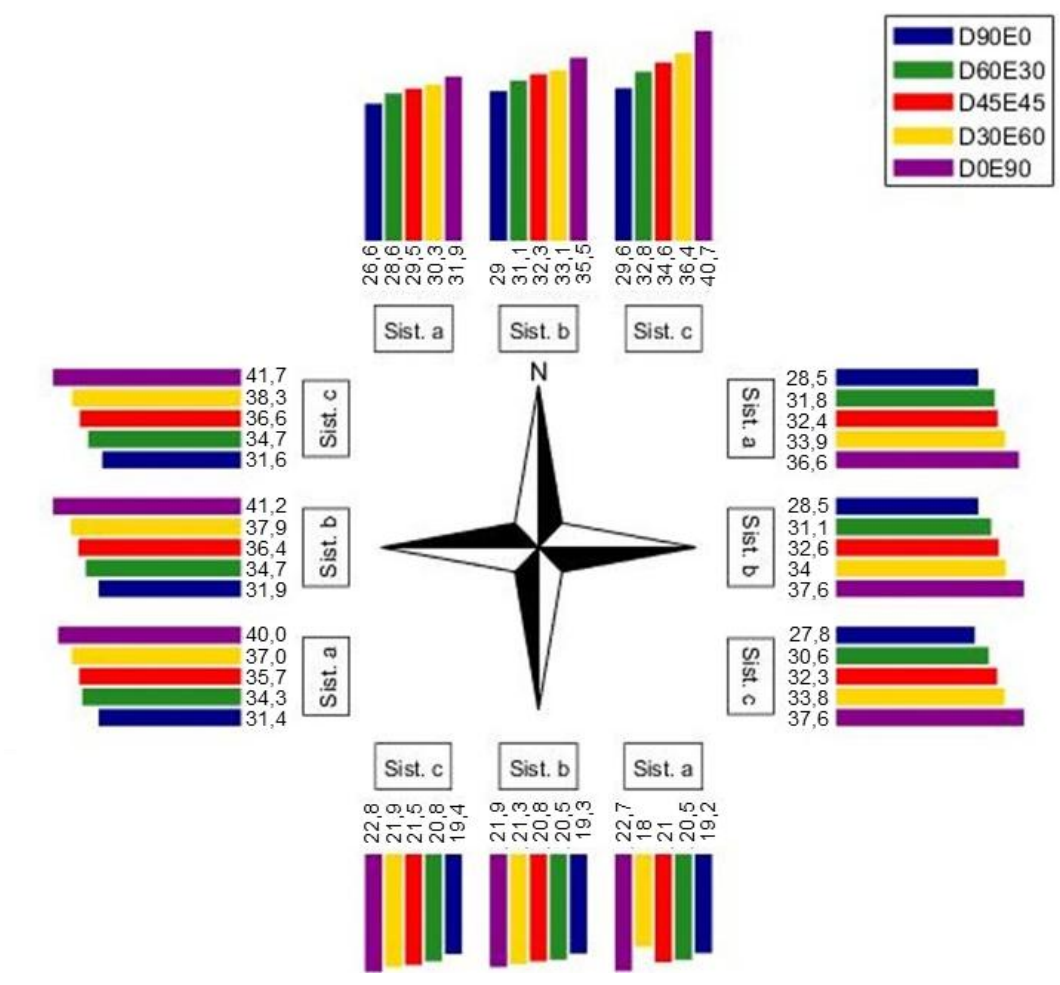

202 Carvalho, M. L. S.; Cabús, R. C. 
$\mathrm{Na}$ orientação leste os ganhos obtidos a partir da variação de reflexão difusa para especular seguem o mesmo comportamento que na orientação norte, sendo de até $35 \%$ no terceiro sistema. No caso da orientação oeste, os ganhos máximos chegam a 32\%. Porém, diferentemente dos resultados da orientação norte, os ganhos observados para leste e oeste apresentaram valores aproximados entre os três sistemas estudados, salientando-se que, também no estudo deste parâmetro, houve menor influência da variação do número de peças. Comparando-se o gráfico da orientação norte com o gráfico da orientação leste, percebe-se que no caso do último houve menor variação entre os três sistemas, confirmando esse comportamento.

No caso da orientação sul percebe-se que os ganhos decorrentes da variação das características de reflexão são menores em comparação com a orientação norte, chegando ao máximo de $18 \%$ no caso do sistema $c$. Em todas as orientações analisadas os três sistemas de dispositivos apresentam padrão de variação semelhante.

Pode-se concluir que a orientação sul é a menos sensível às mudanças das características de reflexão dos dispositivos, bem como foi observado em relação ao aumento no número de peças.

Vale salientar que embora o aumento no número de peças não tenha resultado em ganhos significativos na maioria das situações estudadas, quando se compara os ganhos obtidos a partir do incremento da especularidade nos modelos com mais peças é possível garantir maior eficiência, demonstrando que uma parametrização conjunta pode ser mais interessante para o aproveitamento da luz solar refletida.

\section{Efeitos da variação da refletância}

Nos modelos de cada um dos três sistemas da orientação norte é possível observar que o incremento da refletância dos dispositivos proporciona ganhos no aproveitamento da luz solar. Esses ganhos são maiores entre os modelos de dispositivos com reflexão especular. Entre os parâmetros analisados, o aumento da refletância dos dispositivos resultou em ampliação do índice de eficiência da luz solar refletida, conforme mostra a Figura 6.

No primeiro sistema a variação de refletância entre os modelos com difusividade proporcionou ganhos de $24 \%$ no índice de eficiência. Os modelos especulares chegaram a incrementar até $43 \%$ o índice. Apesar de o aumento no número de peças entre os três sistemas não resultar em aumento da área exposta dos dispositivos, percebe-se que a variação da refletância é capaz de proporcionar maior aproveitamento da luz solar refletida. O terceiro sistema, com o maior número de peças, também manteve o aumento no índice, apresentando maiores valores percentuais em relação aos sistemas com menor número de peças.

Figura 6 - Gráficos de variação do índice de eficiência da luz solar refletida em relação à refletância dos dispositivos. Modelos sem especularidade (à esquerda) e especulares (à direita) - orientações norte, leste, oeste e sul; refletâncias de 10\% a 90\%; norte e sul= Sistema a- 01 peça, Sistema b- 02 peças, Sistema c- 04 peças; leste= Sistema a- 02 peças, Sistema b- 04 peças, Sistema c- 08 peças

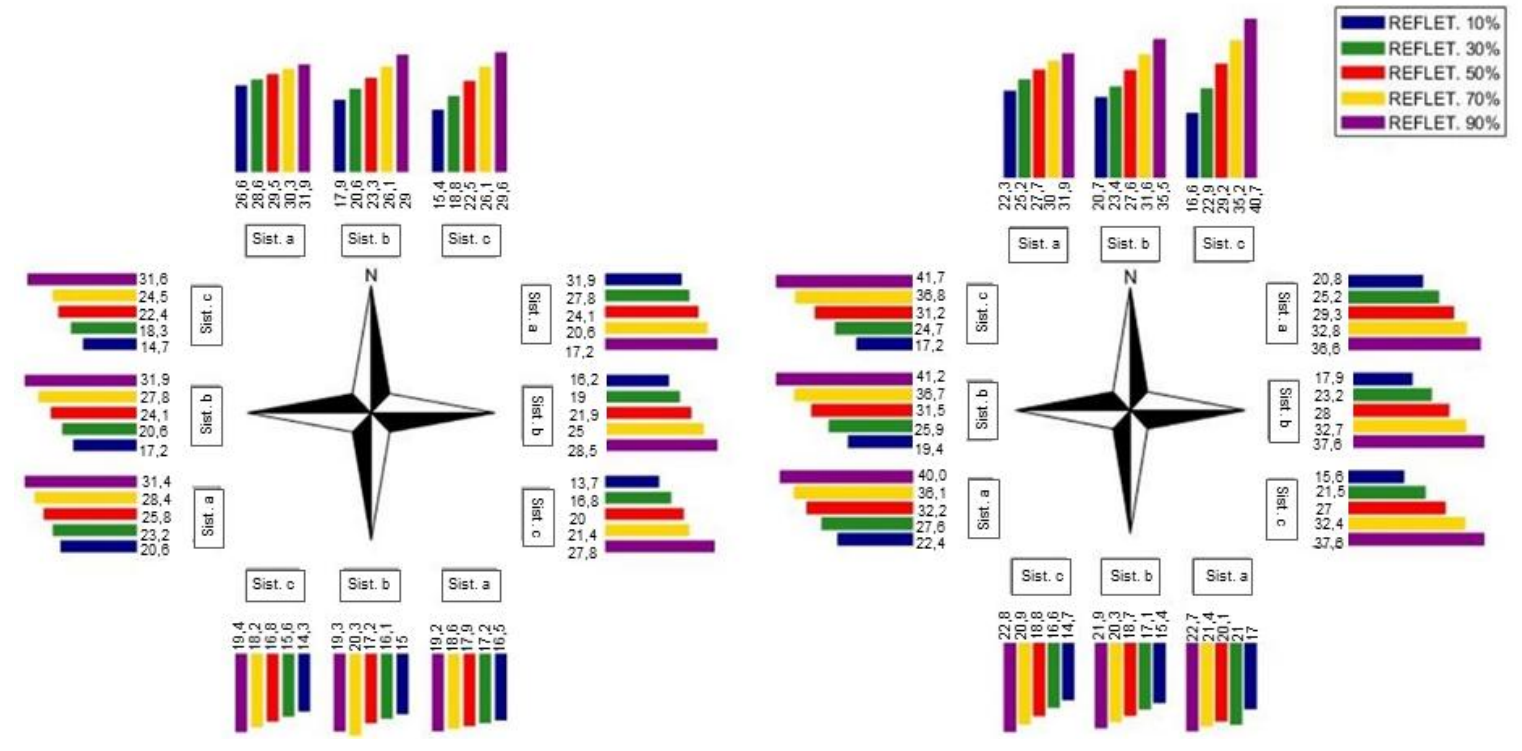


No caso dos modelos difusos, a orientação oeste mostrou-se mais sensível à variação da refletância da superfície dos dispositivos de sombreamento. O primeiro sistema, com menor número de peças, proporcionou aumento de $52 \%$ na eficiência da luz solar refletida a partir da variação de refletância de $10 \%$ para $90 \%$. No terceiro sistema essa tendência de aumento permanece e os ganhos em percentual ficam em $115 \%$. No caso dos modelos especulares, o desempenho da orientação leste e oeste foi aproximado em relação ao aumento da refletância.

A orientação sul apresentou os menores ganhos na eficiência da luz solar refletida a partir do incremento da refletância. $\mathrm{O}$ sistema com maior número de peças proporcionou um aumento de $55 \%$ na eficiência da luz solar refletida entre os modelos especulares de menor e maior refletância, e de $36 \%$ entre os modelos difusos. Os demais sistemas também garantiram ganhos no índice, porém em menores proporções. Observou-se que o incremento da refletância dos dispositivos, juntamente com os outros dois parâmetros, número de peças e especularidade, foram responsáveis por maiores ganhos na eficiência da luz solar refletida. É possível observar que em todas as orientações analisadas os modelos especulares apresentaram maior aumento da eficiência.

\section{Análise estatística dos dados}

Analisando a planilha dos efeitos estimados referente à orientação norte (Tabela 5Erro! Fonte de referência não encontrada.), observa-se que os valores do coeficiente de correlação $\left(\mathrm{R}^{2}\right)$ e do coeficiente de correlação ajustado ( $\mathrm{R}^{2}$ ajust) correspondem, respectivamente, a 0,99 e 0,98, indicando que o modelo estatístico é capaz de explicar as variações dos valores observados na simulação.

Em relação aos efeitos dos parâmetros analisados para a variação do índice de eficiência da luz solar refletida, observa-se que, entre as características dos dispositivos, apenas o número de peças apresentou efeito negativo. Conforme demonstrado na análise exploratória, o aumento do número de peças resultou em redução do índice de eficiência na maioria dos modelos avaliados, principalmente aqueles com menores refletâncias. As demais características apresentaram efeitos positivos, com destaque para a refletância que corresponde à variável com maior influência para a variação do índice.

Quando são analisadas as interações entre duas variáveis independentes, apresentadas na planilha de efeitos estimados, percebe-se que o maior efeito é resultante da interação entre número de peças e refletância dos dispositivos. Durante a análise exploratória foi possível observar que a variação da eficiência da luz solar refletida era ampliada entre modelos pertencentes aos sistemas com maior número de peças.

Os resultados da análise estatística referente à orientação leste estão apresentados na Tabela 6Erro! Fonte de referência não encontrada..

A planilha dos efeitos estimados mostra que mais uma vez a variável número de peças representou impacto negativo para o índice de eficiência da luz solar refletida. A análise exploratória indicou que o aumento do número de peças resultou em redução do índice de eficiência, sobretudo no caso de modelos com menores refletâncias, conforme foi observado em relação à orientação norte. As demais variáveis apresentaram efeitos positivos com valores altos, indicando que sua variação é capaz de resultar em maiores valores de eficiência. A variável "refletância" corresponde à característica de maior impacto dos dispositivos de sombreamento, também na orientação leste. Todas as interações analisadas resultaram em efeitos positivos, porém inferiores àqueles observados individualmente por cada variável. Nota-se que a variável "número de peças" analisada em conjunto com a especularidade é capaz de proporcionar ganhos na eficiência, embora o efeito seja baixo.

Tabela 5 - Análise estatística orientação norte

\begin{tabular}{|c|c|c|c|c|c|}
\hline & \multicolumn{5}{|c|}{ Planilha dos efeitos estimados - norte } \\
\hline & \multirow[b]{2}{*}{ Fator } & \multicolumn{4}{|c|}{$R^{2}=0,99 / R^{2}$ ajust $=0,98$} \\
\hline & & Efeito & $\begin{array}{c}\text { Erro- } \\
\text { padrão }\end{array}$ & Coef. & $\begin{array}{l}\text { Erro-padrão } \\
\text { do coef. }\end{array}$ \\
\hline & Média & 25,61 & 0,15 & 25,61 & 0,15 \\
\hline & 2) Número de peças & $-0,16$ & 0,38 & $-0,08$ & 0,19 \\
\hline & 3) Especularidade & 4,88 & 0,38 & 2,44 & 0,19 \\
\hline & 4) Reflet. dos dispositivos & 13,85 & 0,38 & 6,93 & 0,19 \\
\hline \multirow{2}{*}{$\begin{array}{l}\text { Interação entre } \\
\text { variáveis }\end{array}$} & Entre 2 e 3 & 1,56 & 0,46 & 0,78 & 0,23 \\
\hline & Entre 2 e 4 & 5,52 & 0,46 & 2,76 & 0,23 \\
\hline
\end{tabular}




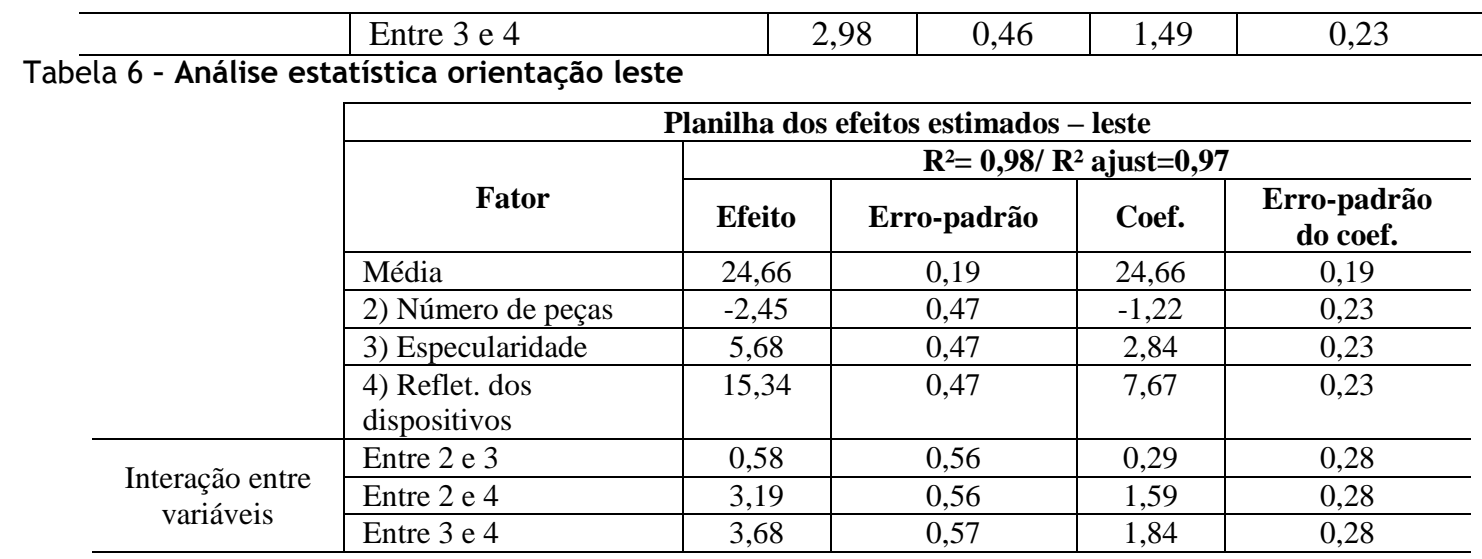

Em relação à orientação oeste, cujo resultado está ilustrado na Tabela 7, percebe-se que todas as variáveis analisadas apresentaram maior impacto para a eficiência da luz solar refletida em comparação com as demais orientações. Conforme observado nos demais casos, a variável "número de peças" apenas é capaz de resultar em ganhos para o índice quando interage com a especularidade e refletância.

A Tabela 8 apresenta os resultados da análise estatística referente à orientação sul. De maneira geral, os efeitos de cada parâmetro seguiram o mesmo padrão de comportamento na orientação leste, porém com valores mais baixos. Os coeficientes de correlação e de correlação ajustado correspondem a valores acima de 0,99 .

Na planilha dos efeitos estimados é possível observar que a variável "número de peças" apresentou efeito negativo para o índice de eficiência da luz solar refletida, como pode ser notado nas análises referentes às orientações leste e norte. Também nesta orientação a variável "refletância dos dispositivos" resultou em maior impacto para o índice de eficiência e, consequentemente, para o aproveitamento da luz solar refletida.

Por meio dos valores fornecidos pela regressão múltipla, método estatístico utilizado, é possível prever, através de uma função (Equação 2), os valores do índice de eficiência da luz solar refletida $\left(\eta_{\mathrm{sr}}\right)$, levando-se em consideração o erro padrão previsto em cada caso.

$\eta_{\mathrm{sr}}=$ Média $+($ Var02 x coef. 2$)+($ Var03 x coef. 3$)+($ Var04 x coef. 4$)$

Eq. 2

Para tanto, são utilizados os valores das médias e dos coeficientes que constam das planilhas de efeitos estimados (ver Tabelas 5 a 8 ) e os valores das categorias estatísticas de cada variável, conforme Tabela 3, com validade confirmada para as faixas das variáveis usadas no ajuste dos parâmetros do modelo.

A partir das análises de todos os parâmetros avaliados nas seções anteriores, é possível concluir que cada orientação possui um potencial diferente para aproveitamento da luz solar refletida e seu consequente direcionamento para o interior do ambiente. Pode-se notar que a presença de elementos capazes de redirecionar a luz solar, bem como a variação de características físicas como a refletância, por exemplo, foi capaz de aumentar o valor da componente de luz solar refletida na iluminância global do ambiente.

Em relação à influência dos parâmetros, representada pelos valores que constam nas tabelas de efeitos estimados, é possível notar que a refletância da superfície é a característica dos dispositivos que mais afeta positivamente o índice de eficiência da luz solar refletida, confirmando o resultado da análise exploratória dos dados. Dessa maneira, em todas as orientações estudadas, aumentar a refletância dos dispositivos tem como resultado o incremento do índice de eficiência. A Tabela 9 resume todos os valores de efeitos encontrados na análise estatística, separando-os por orientação e parâmetro: quanto maior o valor, maior a influência do parâmetro para a eficiência da luz solar refletida.

A variável número de peças também apresentou o mesmo tipo de influência para o índice de eficiência, resultando em efeito negativo em todas as orientações. Foi visto na análise exploratória que essa característica apenas proporcionou ganhos no caso de modelos com alta refletância, diferentemente do que foi observado com a refletância e a especularidade, que garantiram variações positivas importantes no aproveitamento da luz solar para todas as refletâncias.

Entre as quatro orientações, os maiores valores dos efeitos são referentes à orientação oeste, o que indica que a parametrização é capaz de resultar em maiores variações do índice de eficiência da luz solar refletida sob 
essas condições. A orientação sul, como foi observado na análise anterior, proporcionou menor influência da variação das características estudadas.

Tabela 7 - Análise estatística orientação oeste

\begin{tabular}{|c|c|c|c|c|c|}
\hline & \multicolumn{5}{|c|}{ Planilha dos efeitos estimados - oeste } \\
\hline & \multirow[b]{2}{*}{ Fator } & \multicolumn{4}{|c|}{$R^{2}=0,99 / R^{2}$ ajust $=0,99$} \\
\hline & & Efeito & $\begin{array}{c}\text { Erro- } \\
\text { padrão }\end{array}$ & Coef. & $\begin{array}{l}\text { Erro-padrão } \\
\text { do coef. }\end{array}$ \\
\hline & Média & 27,44 & 0,12 & 27,44 & 0,12 \\
\hline & 2) Número de peças & $-2,28$ & 0,29 & $-1,14$ & 0,14 \\
\hline & 3) Especularidade & 6,42 & 0,29 & 3,21 & 0,15 \\
\hline & 4) Reflet. dos dispositivos & 18,03 & 0,29 & 9,02 & 0,15 \\
\hline \multirow{3}{*}{$\begin{array}{c}\text { Interação entre } \\
\text { variáveis }\end{array}$} & Entre 2 e 3 & 0,76 & 0,35 & 0,38 & 0,17 \\
\hline & Entre 2 e 4 & 3,07 & 0,35 & 1,54 & 0,17 \\
\hline & Entre 3 e 4 & 3,62 & 0,36 & 1,81 & 0,18 \\
\hline
\end{tabular}

Tabela 8 - Análise estatística orientação sul

\begin{tabular}{|c|c|c|c|c|c|}
\hline & \multicolumn{5}{|c|}{ Planilha dos efeitos estimados - sul } \\
\hline & \multirow[b]{2}{*}{ Fator } & \multicolumn{4}{|c|}{$R^{2}=0,99 / R^{2}$ ajust $=0,98$} \\
\hline & & Efeito & $\begin{array}{c}\text { Erro- } \\
\text { padrão }\end{array}$ & Coef. & $\begin{array}{c}\text { Erro-padrão } \\
\text { do coef. }\end{array}$ \\
\hline & Média & 18,13 & 0,06 & 18,13 & 0,06 \\
\hline & 2) Número de peças & $-1,22$ & 0,14 & $-0,61$ & 0,07 \\
\hline & 3) Especularidade & 1,82 & 0,15 & 0,91 & 0,07 \\
\hline & 4) Reflet. dos dispositivos & 5,78 & 0,15 & 2,89 & 0,07 \\
\hline \multirow{3}{*}{$\begin{array}{c}\text { Interação entre } \\
\text { variáveis }\end{array}$} & Entre 2 e 3 & $-0,01$ & 0,17 & $-0,01$ & 0,08 \\
\hline & Entre 2 e 4 & 1,46 & 0,17 & 0,73 & 0,08 \\
\hline & Entre 3 e 4 & 1,36 & 0,18 & 0,68 & 0,09 \\
\hline
\end{tabular}

Tabela 9 - Efeitos de cada característica em relação à variação da eficiência da luz solar refletida

\begin{tabular}{c|c|c|c}
\hline Orientação & Número de peças & Especularidade & Refletância dos dispositivos \\
\hline Norte & $-0,16$ & 4,88 & 13,85 \\
Leste & $-2,45$ & 5,68 & 15,34 \\
Oeste & $-2,28$ & 6,42 & 18,03 \\
Sul & $-1,22$ & 1,82 & 5,78 \\
\hline
\end{tabular}

\section{Conclusão}

O presente trabalho teve como objetivo estudar o desempenho de brises em salas de aula com relação ao índice de eficiência da luz solar refletida na cidade de Maceió. Para tanto, foi proposto um índice para avaliação de dispositivos de sombreamento em relação à luz solar refletida. Esse índice é capaz de identificar a contribuição de tais elementos para o aproveitamento da componente de luz solar refletida.

$\mathrm{O}$ índice de eficiência da luz solar refletida $\left(\eta_{\mathrm{sr}}\right)$ proposto para esta pesquisa mostrou-se adequado para o objetivo de quantificar e comparar o desempenho de diversos tipos de dispositivos em relação ao aproveitamento da luz solar e corresponde à principal contribuição deste trabalho. A partir da sua utilização, torna-se possível classificar quaisquer elementos de acordo com seu potencial de redirecionamento da luz solar na forma refletida, para o interior do ambiente. No entanto, é necessário destacar que o índice foi proposto como métrica e que estudos posteriores devem ser desenvolvidos no sentido de classificá-lo por faixas qualitativas. Isso deve ser feito levando-se em consideração a latitude e a consequente geometria de insolação de cada região.

A orientação norte destaca-se por proporcionar maior possibilidade de incremento do índice de eficiência de luz solar refletida a partir do aumento do número de peças, em comparação com as demais orientações analisadas. No entanto, os ganhos no índice foram observados apenas nos casos em que a refletância das peças foi superior a $70 \%$. 
O aumento da especularidade, por sua vez, representou variação positiva do índice nas quatro orientações, embora a refletância tenha sido mantida em $90 \%$. No caso das orientações leste e oeste, o desempenho dos três sistemas apresentou mesmo padrão, comprovando menor influência da variação do número de peças.

As análises mostraram que a refletância corresponde à característica de maior influência para o aproveitamento da luz solar refletida. No caso dos modelos difusos, a orientação oeste mostrou-se mais sensível à variação da refletância da superfície dos dispositivos de sombreamento, chegando a proporcionar aumento de $115 \%$ no índice. A orientação sul apresentou os menores ganhos na eficiência da luz solar refletida a partir do incremento da refletância e também das demais variáveis analisadas.

Algumas recomendações para o projeto de dispositivos de sombreamento na região tropical de baixa latitude podem ser destacadas, diante da variedade de soluções disponíveis, levando-se em consideração as variáveis e os cenários definidos para este estudo. $\mathrm{O}$ aumento do número de peças em sistemas com maiores refletâncias e o emprego de superfícies especulares voltadas para oeste, por exemplo, proporcionam maior aproveitamento da luz solar refletida.

Tais soluções caracterizam-se, de modo geral, como medidas simples, como a inserção de peças, substituição de material empregado ou, simplesmente, a escolha de acabamento com maior refletância para os elementos de proteção, e são passíveis de aplicação tanto durante a fase de projeto, quanto posteriormente, na busca pela otimização de um sistema existente.

Como limitação da pesquisa, deve-se destacar que o ambiente-modelo não foi analisado em relação ao efeito do ofuscamento para o desconforto luminoso do usuário. Sugere-se, como possibilidades de trabalhos futuros, a análise do ofuscamento causado pelas peças visíveis a partir do ponto de vista do observador e a análise da variação do índice de eficiência de luz solar refletida em localidades com diferentes latitudes para que sejam avaliados os efeitos da geometria da insolação nos resultados encontrados.

\section{Referências}

BAKER, N.; STEEMERS, K. Daylight Design of Buildings. London: James \& James, 2002.

BARRETT, P. et al. The impact of classroom design on pupils' learning: final results of a holistic, multilevel analysis. Building and Environment, v. 89, p. 118-133, 2015.

BECKER, A. et al. Diagnostico Casa Hacienda Quilapilún: asesoría en eficiencia energética y calidad ambiental. In:UNIVERSIDAD AUSTRAL DO CHILE (Org.). Dossier Laboratorio de Estudios de Sustentabilidad, Instituto de Arquitectura y Urbanismo. Valdivia: UAC, 2011.

BELTRÁN, L.; PAPAMICHAEL, K.; SELKOWITZ, S. Advanced optical daylighting systems: light shelves and light pipes. Journal of the Illuminating Engineering Society, v. 26, p. 91-106, 1997.

BOYCE, P. R. The impact of light in buildings on human health. In: INTERNATIONAL CONFERENCE ON SUSTAINABLE HEALTHY BUILDINGS, 2., Seoul, 2009.Proceedings [...] Seoul, 2009.

CABÚS, R. C. The influence of ground-reflected light in tropical daylighting. In: PASSIVE AND LOW ENERGY ARCHITECTURE, Lyon, 2002. Proceedings [...] Lyon, 2002.

CABÚS, R. C. TropLux: um sotaque tropical na simulação da luz natural em edificações. In: ENCONTRO LATINO-AMERICANO, 4.; ENCONTRO NACIONAL SOBRE CONFORTO NO AMBIENTE CONSTRUÍDO, 8., Maceió, 2005. Anais [...] Porto Alegre: ANTAC, 2005.

CABÚS, R. C.; RIBEIRO, P. V. S. TropLux 7 - Guia do Usuário. Maceió: Instituto Lumeeiro, 2015.

CARTANA, R. P.; PEREIRA, F. O. R.; BERTÉ, E. J. Avaliação de desempenho térmico e lumínico de elementos de controle solar projetados através de modelagem paramétrica. In: ENCONTRO NACIONAL DE TECNOLOGIA DO AMBIENTE CONSTRUÍDO, 16., São Paulo, 2016.Anais [...]São Paulo: ANTAC, 2016.

CHAN, Y.; TZEMPELIKOS, A. Efficient venetian blind control strategies considering daylight utilization and glare protection. Solar Energy, v. 98, p. 241-254, 2013.

COMMISSION INTERNATIONALE DE L'ECLAIRAGE. DS 011.2/E:spatial distribution of daylight: CIE standard general sky. Viena, 2002.

DUBOIS, M. Shading devices and daylight quality: an evaluation based on simple performance indicators. Lighting, Research and Technology, v. 35, p. 61-76, 2003. 
ELETROBRAS-PROCEL. Manual para Aplicação do RTQ-R. Rio de Janeiro: Eletrobrás. 2012.

ELTAWEEL, A.; YUEHONG, S. Using integrated parametric control to achieve better daylighting uniformity in an office room: a multi-step comparison study. Energy and Buildings, v. 152, p. 137-148, 2017.

FIUZA, J. M.; CLARO, A. Influência de elementos de proteção solar horizontais aplicados a aberturas laterais na admissão e distribuição da luz natural. In: ENCONTRO NACIONAL, 10.; ENCONTRO LATINO AMERICANO DE CONFORTO NO AMBIENTE CONSTRUÍDO, 6., Natal, 2009.Anais [...] Natal: ENCAC-ELACAC, 2009.

GUTIÉRREZ, R. et al. Daylight control and performance in office buildings using a novel ceramic louvre system. Building and Environment, v. 151, p. 54-74, 2019.

HAREDY, A. Simulation of photovoltaic airflow windows for indoor thermal and visual comfort and electricity generation. Nottingham, 2016. 295 f. Tese (Doutorado em Arquitetura e Clima Urbano) Departamento de Arquitetura e Clima Urbano, Universidade de Nottingham, Nottingham, 2016.

HESCCHONG MAHONE GROUP. Windows and Classrooms: astudy of student performance and the indoor environment. Technical report. October, 2003.

HOPKINSON, R. G.; PETHERBRIDGE, P.; LONGMORE, J. Iluminação natural. Lisboa: Fundação Calouste Gulbenkian, 1975.

ILLUMINATING ENGINEERING SOCIETY OF NORTH AMERICA. The Lighting Handbook: reference \& applications. New York, 2011.

KIM, J. T.; KIM, G. Advanced external shading device to maximize visual and view performance. Indoor and Built Environment, v. 19, p. 65-72, 2010.

KONIS, K.; LEE, E. Measured daylighting potential of a static optical louver System under real sun and sky conditions. Building and Environment, v. 92, p. 347-359, 2015.

KONTADAKIS, A. et al. An active sunlight redirection system for daylight enhancement beyond the perimeter zone. Building and Environment, v. 113, p. 267-279, 2017.

LAM, W. M. C. Sunlighting as formgiver for architecture. New York: Van Nostrand Reinhold, 1986.

LAMBERTS, R.; DUTRA, L.; PEREIRA, F. Eficiência Energética na Arquitetura. 3. ed. Rio de Janeiro: Eletrobrás/PROCEL. 2014.

LARANJA, A. C. Parâmetros urbanos e a disponibilidade de iluminação natural no ambiente interno Rio de Janeiro. Rio de Janeiro, 2010. Tese (Doutorado em Arquitetura) - Programa de Pós-Graduação em Arquitetura, Universidade Federal do Rio de Janeiro, Rio de Janeiro, 2010.

LEAL, L. de Q.; LEDER, S. M. Iluminação natural e ofuscamento: estudo de caso em edifícios residenciais multipavimentos. Ambiente Construído, Porto Alegre, v. 18, n. 4, p. 97-117, out./dez. 2018.

LEUNG, T.; RAJAGOPALAN, P.; FULLER, R. Performance of a daylight guiding system in an office building. Solar Energy, v. 94, p. 253-265, 2013.

LI, D. et al. Simple method for determining daylight illuminance in a heavily obstructed environment. Building and Environment, v. 44, p. 1074-1080, 2009.

LIMA, K. M.; BITTENCOURT, L. S. Efeito do espaçamento, inclinação e refletância de brises horizontais com mesma máscara de sombra na iluminação natural e ganhos térmicos em escritórios em Maceió-AL. In: ENCONTRO NACIONAL DE TECNOLOGIA DO AMBIENTE CONSTRUÍDO, 14., Luiz de Fora, 2012.Anais [...] Juiz de Fora: ANTAC, 2012.

LIMA, K. M.; CARAM, R. M. Avaliação de sistemas de janela para suporte a decisões de projeto quanto ao equilíbrio de ganhos de luz e calor. Ambiente Construído, Porto Alegre, v. 15, n. 3, p. 117-133, jul./set. 2015.

MANGKUTO, R.; ROHMAH, M.; ASRI, A. Design optimisation for window size, orientation, and wall reflectance with regard to various daylight metrics and lighting energy demand: A case study of buildings in the tropics. Building and Environment, v. 164, p. 211-219, 2018. 
MANHAS, M. P. G. Difusa ou especular? Estudando o desempenho da prateleira de luz Segundo a refletância de sua superfície. Maceió, 2016. 212 f. Dissertação (Mestrado em Arquitetura e Urbanismo) Programa de Pós-graduação em Dinâmicas do Espaço Habitado, Universidade Federal de Alagoas, Maceió, 2016.

MARDALJEVIC, J. et al. Daylighting metrics for residential buildings. In: SESSION OF THE CIE, 27. Sun City, 2011. Proceedings [...] Sun City, 2011.

PEREIRA, F. O. R. Luminous and thermal performance of windows shading and sunlighting reflecting devices. Shelfield, 1992. Tese (Doutorado em Arquitetura) - University of Shelffield, Shelffield, 1992.

RAMOS, G.; GHISI, E. Analysis of daylight calculated using the EnergyPlus programme. Renewable and Sustainable Energy Reviews, v. 14, p. 1948-1958, 2010.

RIBEIRO, P. V. S.; CABÚS, R. C. Estudo do ângulo de aplicação de painéis prismáticos tipo laser cut em ambiente nos trópicos. In: ENCONTRO NACIONAL, 13.; ENCONTRO LATINO-AMERICANO DE CONFORTO NO AMBIENTE CONSTRUÍDO, 9., Campinas, 2015.Anais [...] Campinas: ANTAC, 2015.

SILVA, J. S. Estratégias para luz natural: sistemas convencionais e brise-soleil como elemento de controle. Paranóa - Cadernos de Arquitetura e urbanismo, Universidade de Brasília, Brasília, v. 3, p. 22-35, 2014.

SOUZA, R. V. G; SANTOS, I. G. Proteções solares no Regulamento Brasileiro de Eficiência Energética de Edifícios Comerciais, de Serviços e Públicos. Ambiente Construído, Porto Alegre, v. 12, n. 1, p. 227-241, jan./mar. 2012.

TREGENZA, P. The Monte Carlo method in lighting calculations. Lighting, Research and Technology, v. 15 , p. $163-170,1983$.

TREGENZA, P.; WATERS, I. Daylight coefficients. Lighting, Research and Technology, v. 15, p. 62-71, 1983.

WAGDY, A. et al. Daylighting simulation for the configuration of external sun-breakers on south oriented windows of hospital patient rooms under a clear desert sky. Solar Energy, v. 149, p. 164-175, 2017.

WARD, G. J.; RUBINSTEIN, F. M. A new technique for computer simulation of illuminated spaces. Journal of the Illuminating Engineering Society, v. 17, p. 80-91, 1988.

WENA, L.; HIYAMA, K.; KOGANEI, M. A method for creating maps of recommended window-to-wall ratios to assign appropriate default values in design performance modeling: a case study of a typical office building in Japan. Energy \& Buildings, v. 145, p. 304-317, 2017.

\section{Marlise Lila Silva Carvalho}

Superintendência de Infraestrutura | Universidade Federal de Alagoas | Av. Lourival Melo Mota, s/n, Cidade Universitária | Maceió - AL Brasil | CEP 57072-900 | Tel.: (82) 3214-1510 | E-mail: marlise.carvalho@gmail.com

\section{Ricardo Carvalho Cabús}

Centro de Tecnologia | Universidade Federal de Alagoas | Tel.: (82) 3214-1311 | E-mail: r.cabus@ctec.ufal.br

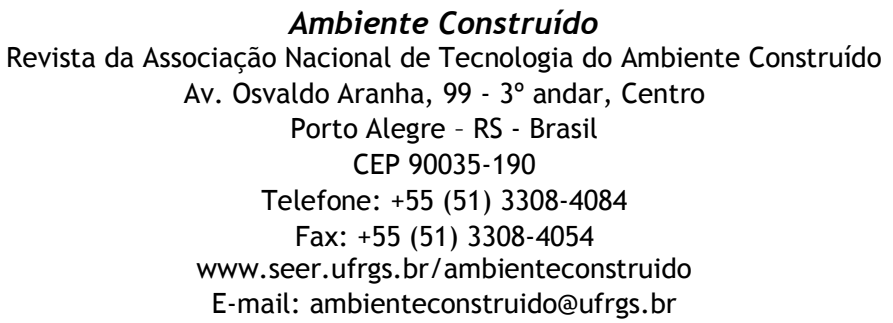

